\title{
New Wideband Notch Antennas for Communication Systems
}

\author{
Albert Sabban \\ Electrical Engineering Department, Ort Braude College, Karmiel, Israel \\ Email:sabban@netvision.net.il \\ Received 1 March 2016; accepted 11 April 2016; published 14 April 2016 \\ Copyright (C) 2016 by author and Scientific Research Publishing Inc. \\ This work is licensed under the Creative Commons Attribution International License (CC BY). \\ http://creativecommons.org/licenses/by/4.0/ \\ (c) (i) Open Access
}

\begin{abstract}
Wireless communication industry is in rapid growth in the last years. Due to the huge progress in development of communication systems in the last decade development of wideband communication systems is continuous growth. However, development of wideband efficient antennas is one of the major challenges in development of wideband wireless communication systems. Low cost compact antennas are crucial in the development of communication systems. Printed notch antennas and miniaturization techniques are employed to develop efficient compact notch antennas. Fractal technology is used to improve the electrical performance and efficiency of notch antennas. Design tradeoffs, computed and measured results of wideband notch antennas with high efficiency are presented in this paper. All antennas are analyzed by using $3 \mathrm{D}$ full-wave software. The paper presents new compact Ultra-Wideband notch antenna $1 \mathrm{GHz}$ to $6 \mathrm{GHz}$, a wideband notch antenna 2.1 GHz to $7.8 \mathrm{GHz}$ and a $5.8 \mathrm{GHz}$ to $18 \mathrm{GHz}$ fractal notch antenna.
\end{abstract}

\section{Keywords}

Notch Antennas, Fractal Antennas, Printed Antennas, Wireless Communication

\section{Introduction}

This paper is a research on new wideband notch antennas for communication systems. Compact printed antennas are crucial in the development of communication systems. However, compact printed antennas suffer from narrow bandwidth and low efficiency. Fractal technology is used to improve the electrical performance and efficiency of notch antennas. Design tradeoffs, computed and measured results of wideband notch antennas with high efficiency are presented in this paper. The paper presents new compact ultra-wideband notch antenna 1 $\mathrm{GHz}$ to $6 \mathrm{GHz}$ and a wideband notch antenna $2.1 \mathrm{GHz}$ to $7.8 \mathrm{GHz}$. A fractal antenna is an antenna that uses antenna design with similar fractal segments to maximize the antenna effective area. Fractal antennas are also referred as multilevel structure with space filling curves. The key aspect lies in a repetition of a motif over two or 
more scale sizes or "iterations”. Fractal antennas are very compact, multiband or wideband, and have useful applications in cellular telephone and microwave communications. Several fractal antennas are presented in books, papers and patents, see [1]-[15]. Compact printed antennas are presented in journals and books, see [16]-[22].

\section{New Fractal Compact Ultra-Wideband, $1 \mathrm{GHz}$ to $6 \mathrm{GHz}$, Notch Antenna}

Fractal geometries may be applied to design antennas and antenna arrays. The advantages of printed circuit technology and printed antennas enhance the design of fractal printed antennas and microwave components. The effective area of a fractal antenna is significantly higher than the effective area of a regular printed antenna. Fractal antenna may operate with good performance at several different frequencies simultaneously. Fractal antennas are compact multiband antennas. Directivity of fractal antennas is usually higher than directivity of a regular printed antenna. The number of element in a fractal antenna array may be reduced by around a quarter of the number of elements in a regular array. A fractal antenna could be considered as a non-uniform distribution of radiating elements. Each of the elements contributes to the total radiated power density at a given point with a given amplitude and phase. By spatially superposing these line radiators we can study the properties of a fractal antenna array. Figure 1 presents Hilbert fractal curves which can be used as space-filling curves.

A wideband notch antenna with fractal structure has been designed. The antenna is printed on RT-DUROID 5880 dielectric substrate with dielectric constant of 2.2 and $1.2 \mathrm{~mm}$ thick. The notch antenna is shown in Figure 2. The notch antenna dimensions are $74.5 \times 57.1 \mathrm{~mm}$. The antenna center frequency is $2.75 \mathrm{GHz}$. The antenna bandwidth is around 200\% for S11 lower than $-6.5 \mathrm{~dB}$, as presented in Figure 3. The notch antenna VSWR is better than $3: 1$ for frequencies from $1 \mathrm{GHz}$ to $5.5 \mathrm{GHz}$. The antenna beam width is around $84^{\circ}$. The antenna gain is around3.5dBi as presented in Figure 4. $\mathrm{H}$ plane radiation pattern of the wideband notch antenna with fractal structure is presented in Figure 5.

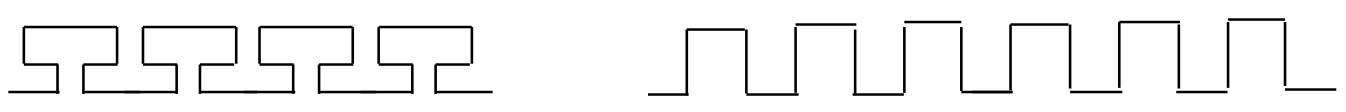

Figure 1. Hilbert fractal curves which can be used as space-filling curves.

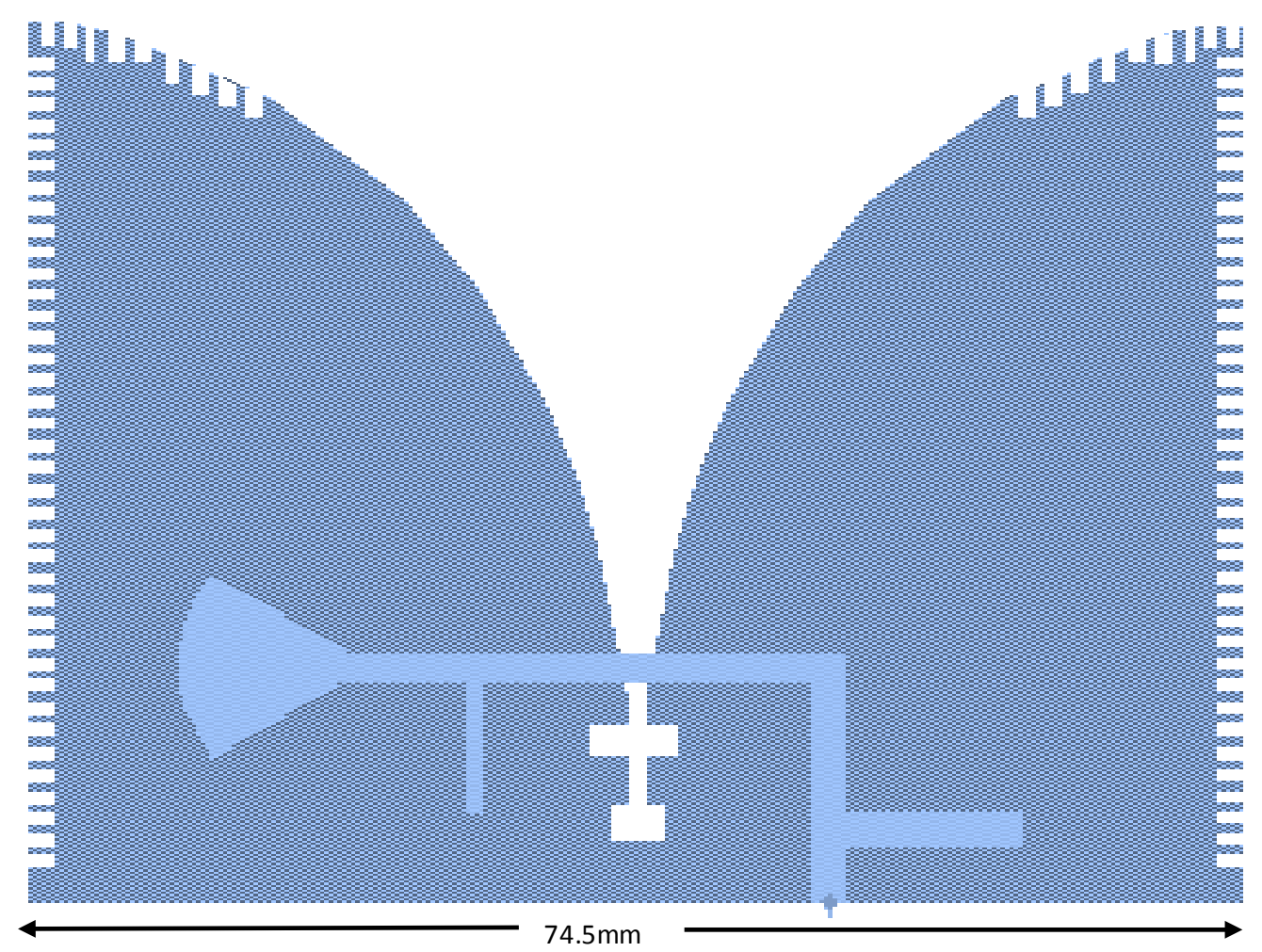

Figure 2. A wideband notch antenna with fractal structure. 


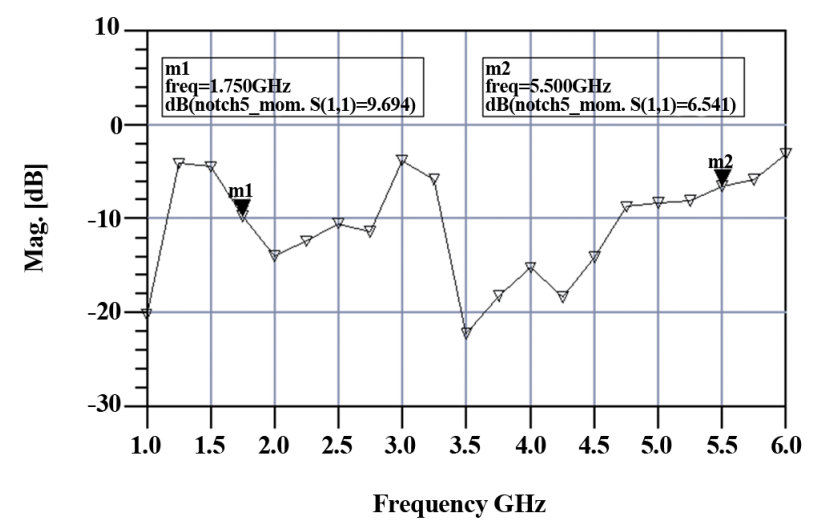

Figure 3. A wideband notch antenna with fractal structure, computed S11.

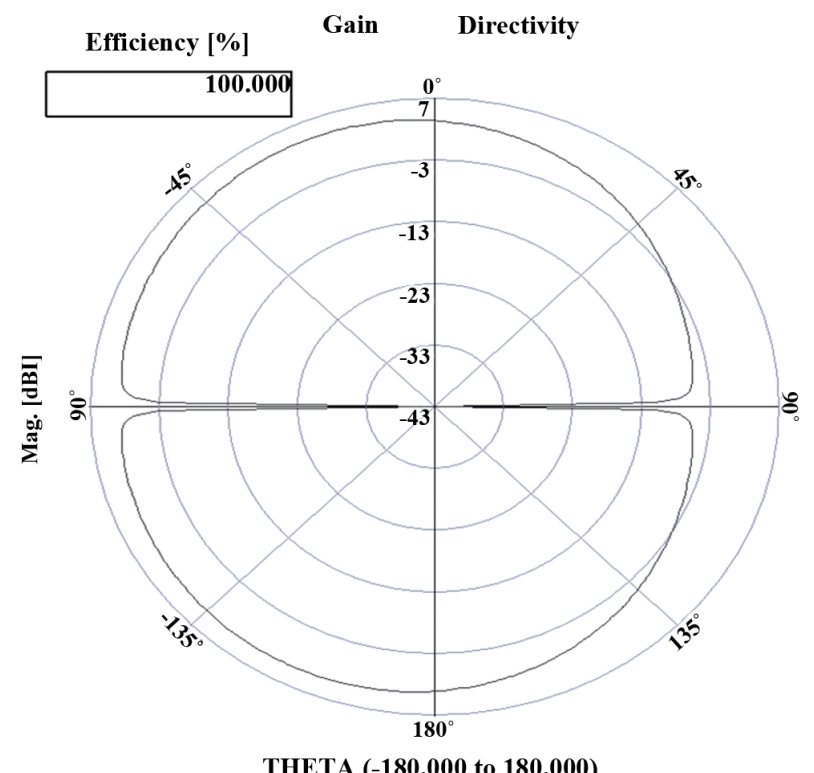

Figure 4. E plane radiation pattern of the wideband notch antenna with fractal structure.

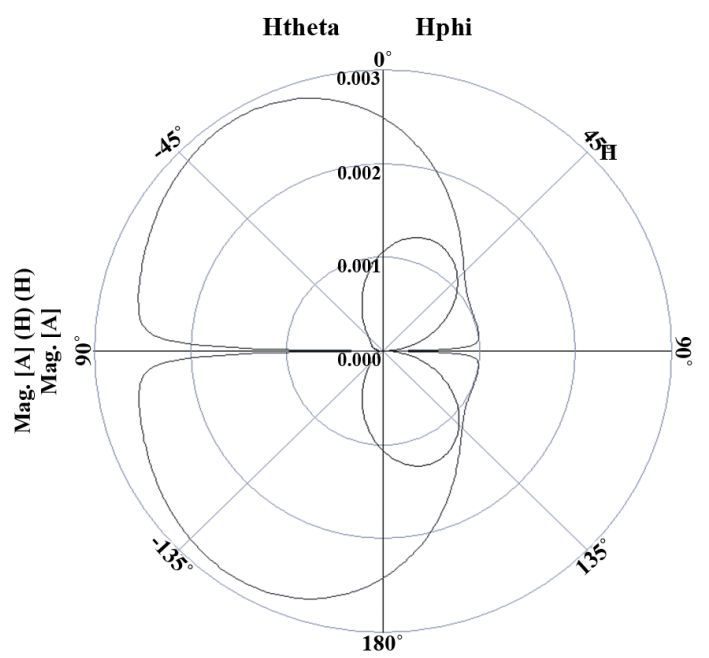

THETA (-180.000 to 180.000$)$

Figure 5. H plane radiation pattern of the wideband notch antenna with fractal structure. 


\section{New Compact Ultra-Wideband Notch Antenna $1.3 \mathrm{GHz}$ to $3.9 \mathrm{GHz}$}

A wideband notch antenna with fractal structure has been designed. The antenna is printed on RT-DUROID 5880 dielectric substrate with dielectric constant of 2.2 and $1.2 \mathrm{~mm}$ thick. The notch antenna is shown in Figure 6. The notch antenna dimensions are $52.2 \times 36.8 \mathrm{~mm}$. The antenna center frequency is $2.7 \mathrm{GHz}$. The antenna bandwidth is around $100 \%$ for S11 lower than $-6.5 \mathrm{~dB}$, as presented in Figure 7 . The notch antenna VSWR is better than 3:1 for frequencies from $1.3 \mathrm{GHz}$ to $3.9 \mathrm{GHz}$. The antenna beam width is around $84^{\circ}$. The antenna gain is around $3.5 \mathrm{dBi}$.

\section{Wideband Notch Antenna $2.1 \mathrm{GHz}$ to $7.8 \mathrm{GHz}$}

A wideband notch antenna has been designed. The antenna is printed on RT-DUROID 5880 dielectric substrate with dielectric constant of 2.2 and $1.2 \mathrm{~mm}$ thick. The notch antenna is shown in Figure 8. The notch antenna dimensions are $116.4 \times 71.4 \mathrm{~mm}$. The notch antenna dimensions with fractal structure are $52.2 \times 36.8 \mathrm{~mm}$. The antenna center frequency is $5 \mathrm{GHz}$. The antenna bandwidth is around 100\% for S11 lower than $-6.5 \mathrm{~dB}$, as presented in Figure 9. The notch antenna VSWR is better than 3:1 for frequencies from 2.1 GHz to 7.8 GHz. The antenna beam width is around $84^{\circ}$. The antenna gain is around $2.5 \mathrm{dBi}$. Figure 10 present the radiation pattern of the wideband notch antenna at $3.5 \mathrm{GHz}$.

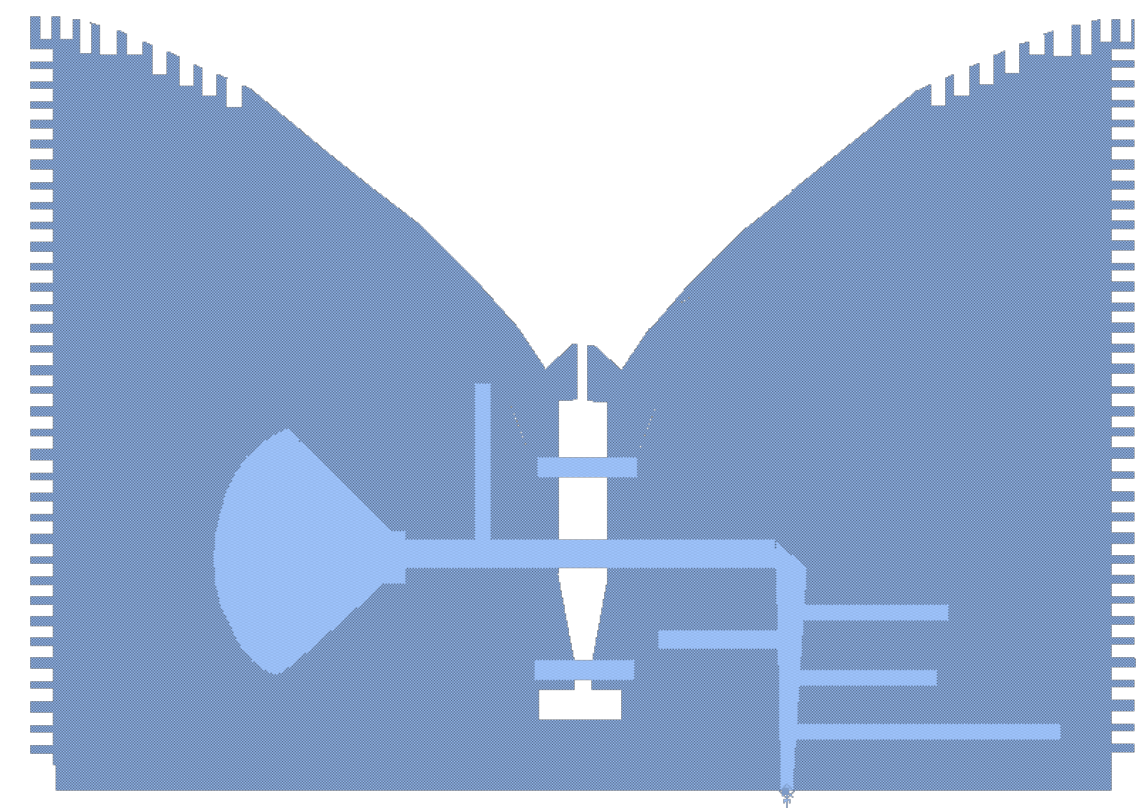

Figure 6. A wideband $1.3 \mathrm{GHz}$ to $3.9 \mathrm{GHz}$ notch antenna with fractal structure.

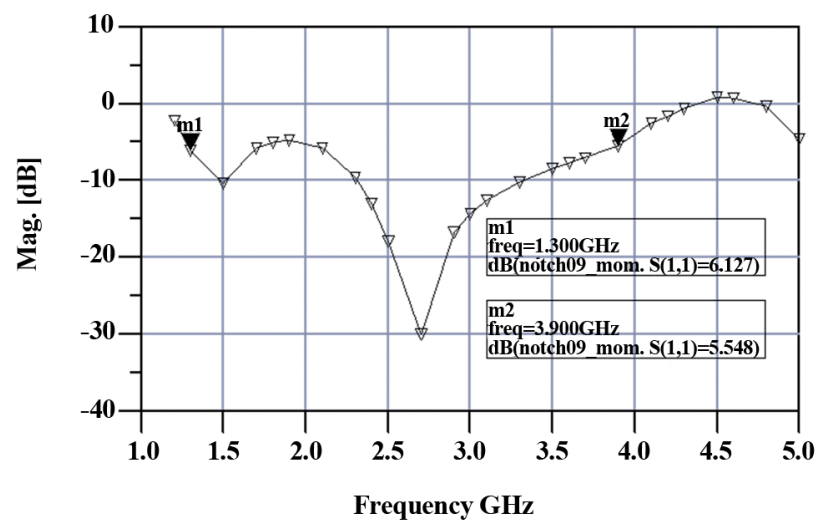

Figure 7. A wideband $1.3 \mathrm{GHz}$ to $3.9 \mathrm{GHz}$ notch antenna with fractal structure, S11 results. 


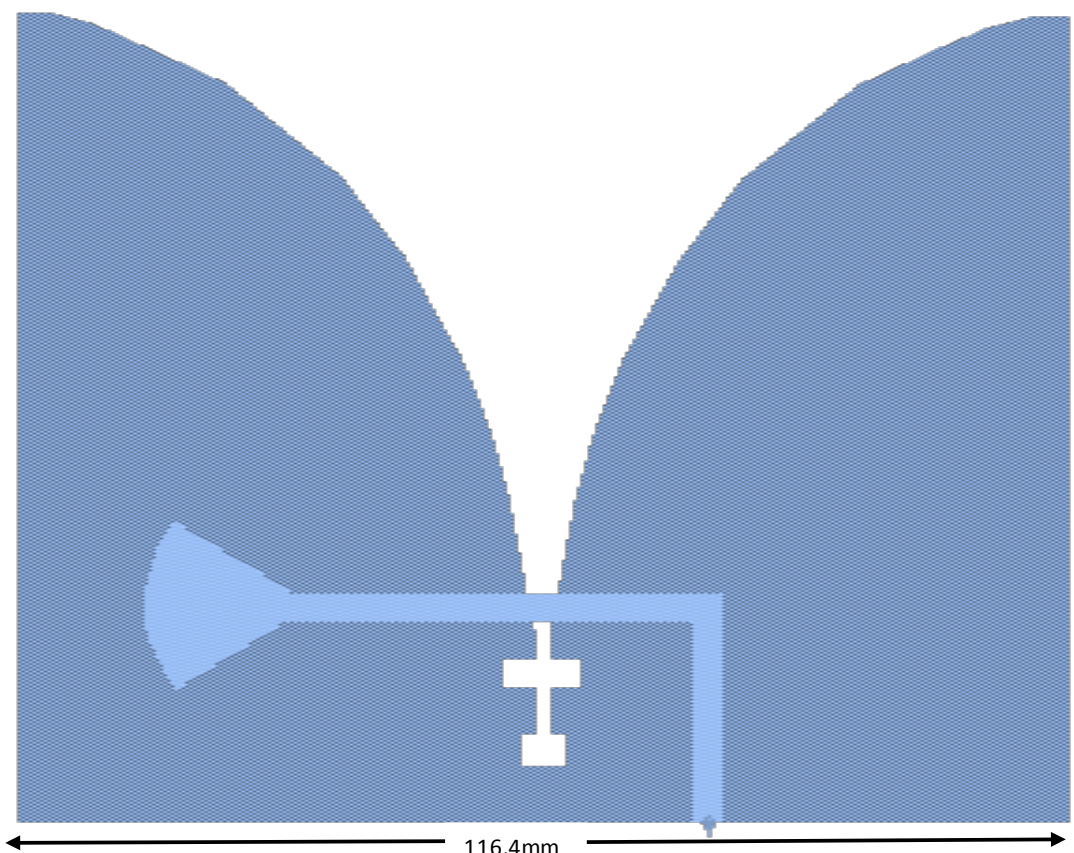

Figure 8. A wideband $2.1 \mathrm{GHz}$ to $7.8 \mathrm{GHz}$ notch antenna.

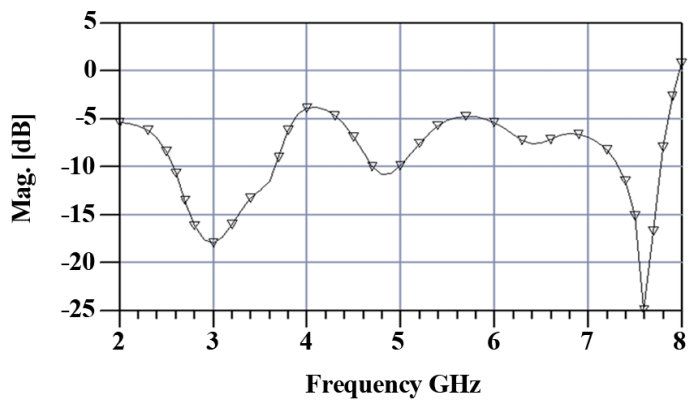

Figure 9. A wideband $2.1 \mathrm{GHz}$ to $7.8 \mathrm{GHz}$ notch antenna, computed S11.

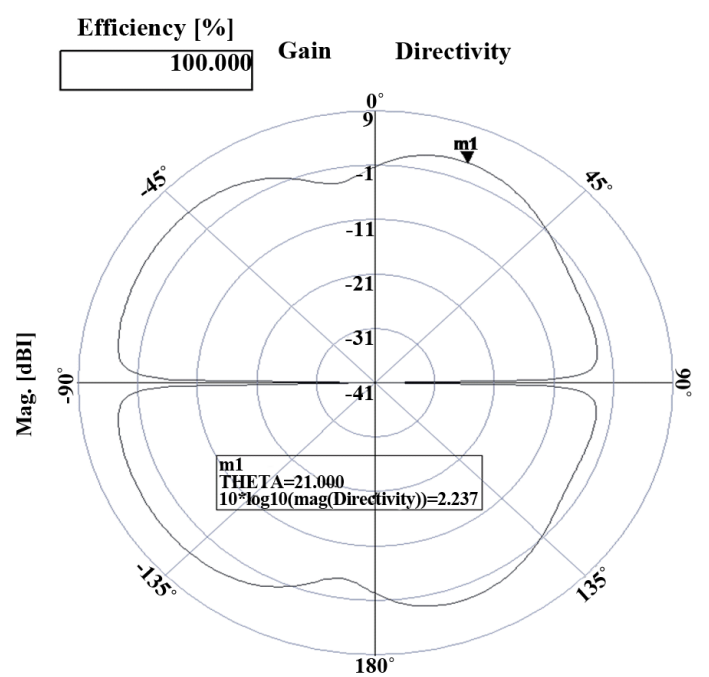

THETA (-180.000 to 180.000$)$

Figure 10. Radiation pattern of the wideband notch antenna at $3.5 \mathrm{GHz}$. 


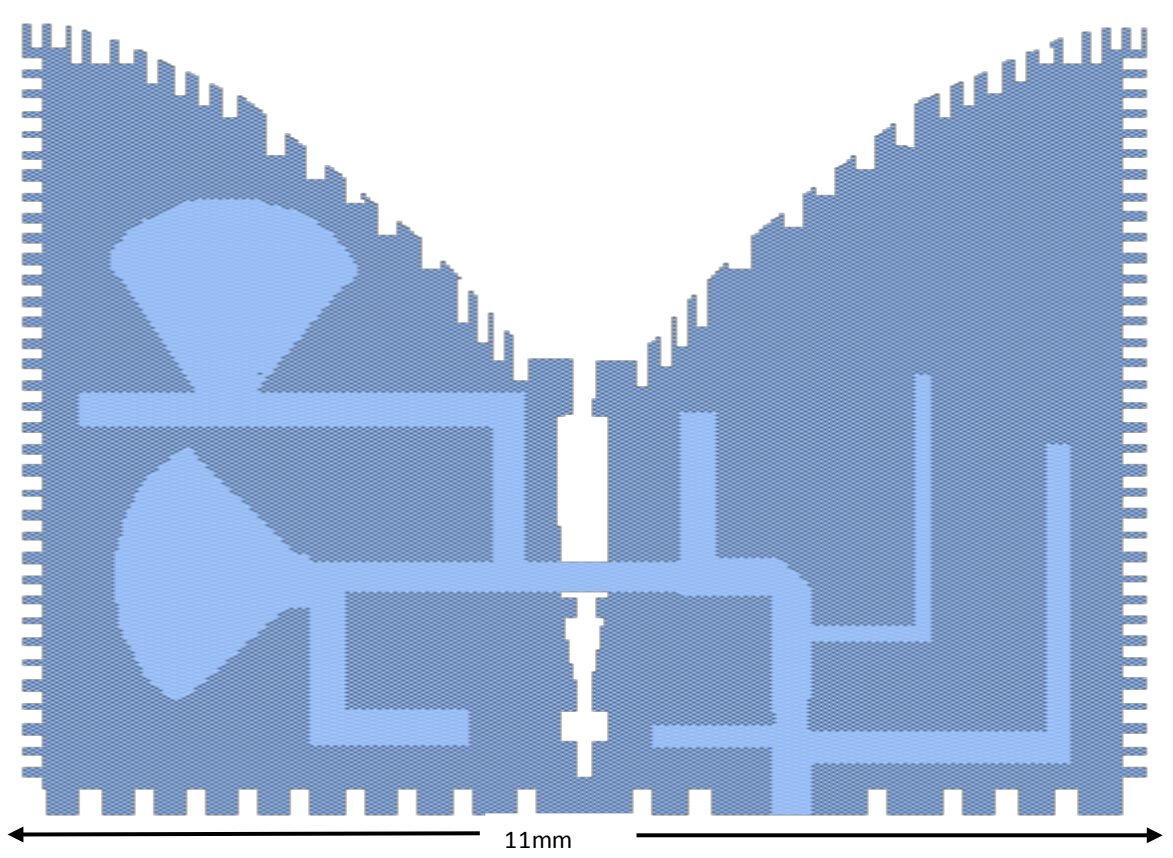

Figure 11. A wideband $5.8 \mathrm{GHz}$ to $18 \mathrm{GHz}$ notch antenna with fractal structure.

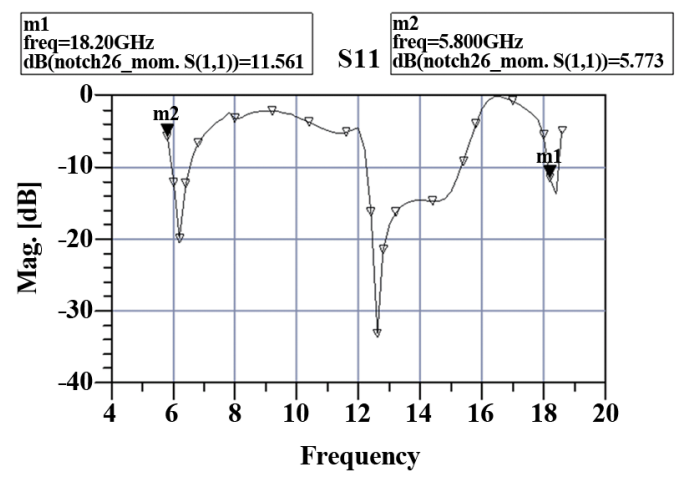

Figure 12. A wideband $5.8 \mathrm{GHz}$ to $18 \mathrm{GHz}$ notch antenna with fractal structure, S11 results.

By using fractal structure the notch antenna length and width was reduced by around $50 \%$.

\section{New Compact Ultra-Wideband Notch Antenna $5.8 \mathrm{GHz}$ to $18 \mathrm{GHz}$}

A wideband notch antenna with fractal structure has been designed. The antenna is printed on RT-DUROID 5880 dielectric substrate with dielectric constant of 2.2 and $1.2 \mathrm{~mm}$ thick. The notch antenna is shown in Figure 11. The notch antenna dimensions are $11 \times 7.7 \mathrm{~mm}$. The antenna center frequency is $12 \mathrm{GHz}$. The antenna bandwidth is around 100\% for S11 lower than $-5 \mathrm{~dB}$, as presented in Figure 12. The notch antenna VSWR is better than 3:1 for more than $90 \%$ of the frequency range from $5.8 \mathrm{GHz}$ to $18 \mathrm{GHz}$. The antenna beam width is around $84^{\circ}$. The antenna gain is around $3.5 \mathrm{dBi}$. Figure 13 presents the radiation pattern of the wideband notch antenna with fractal structure at $8 \mathrm{GHz}$.

The antenna matching network was optimized to get better S11 results at $16 \mathrm{GHz}$ to $18 \mathrm{GHz}$. The length and width of the stubs were tuned to get better S11 results at $16 \mathrm{GHz}$ to $18 \mathrm{GHz}$.

\section{Conclusion}

The paper presents new compact ultra-wideband notch antenna $1 \mathrm{GHz}$ to $6 \mathrm{GHz}$ and a wideband notch antenna $5.8 \mathrm{GHz}$ to $18 \mathrm{GHz}$. Space filling technique and Hilbert curves are employed to design the fractal notch 


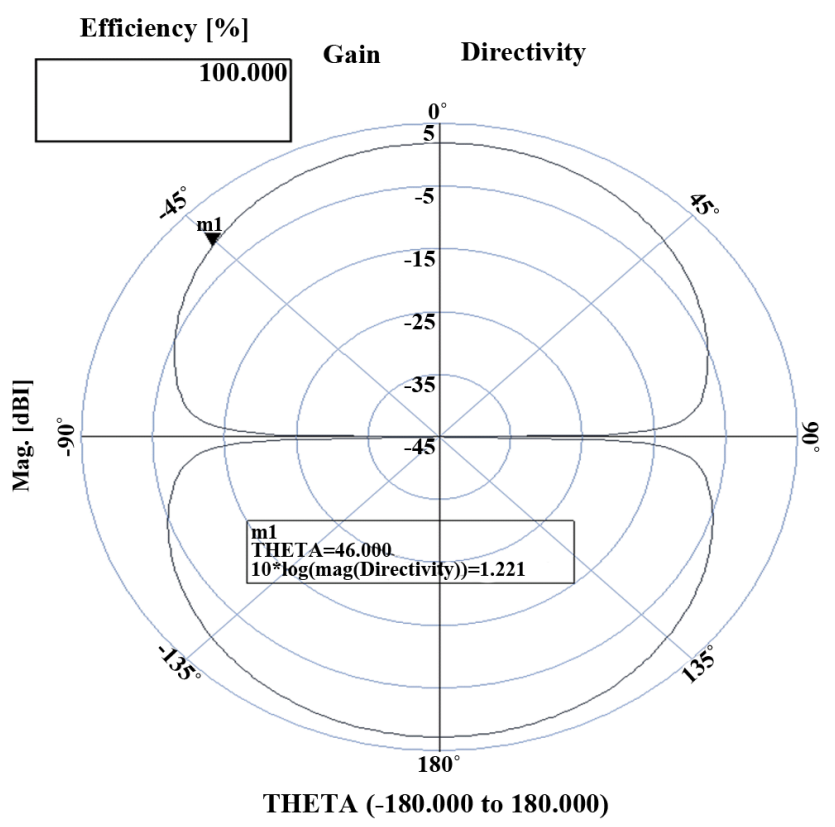

Figure 13. Radiation pattern of the wideband notch antenna with fractal structure at $8 \mathrm{GHz}$.

antennas. The fractal notch antennas are analyzed by using 3D full-wave software. The antenna bandwidth is around $100 \%$ with VSWR better than 3:1. The antenna gain is around $3.5 \mathrm{dBi}$ with efficiency higher than $90 \%$. By using fractal structure, the notch antenna length and width can be reduced by up to $50 \%$.

\section{References}

[1] Mandelbrot, B.B. (1983) The Fractal Geometry of Nature. W.H. Freeman and Company, Canada.

[2] Mandelbrot, B.B. (1967) How Long Is the Coast of Britain? Statistical Self-Similarity and Fractional Dimension. Science, 156, 636-638. http://dx.doi.org/10.1126/science.156.3775.636

[3] Falkoner, F.J. (1990) The Geometry of Fractal Sets. Cambridge Univ. Press, England.

[4] Balanis, C.A. (1997) Antenna Theory Analysis and Design. 2nd Edition, John Wiley \& Sons, Inc., Hoboken.

[5] Virga, K. and Rahmat-Samii, Y. (1997) Low-Profile Enhanced-Bandwidth PIFA Antennas for Wireless Communications Packaging. IEEE Trans. on Microwave Theory and Techniques, 45, 1879-1888. http://dx.doi.org/10.1109/22.641786

[6] Skolnik, M.I. (1981) Introduction to Radar Systems. Mc. Graw Hill, London.

[7] Patent US 5087515, Patent US 4976828, Patent US 4763127, Patent US 4600642, Patent US 3952307, Patent US 3725927.

[8] European Patent Application EP 1317018 A2/27.11.2002

[9] Chiou, T. and Wong, K. (2001) Design of Compact Microstrip Antennas with a Slotted Ground Plane. IEEE-APS Symposium, Boston, 8-12 July 2001.

[10] Hansen, R.C. (1981) Fundamental Limitations on Antennas. Proceedings of the IEEE, 69, 170-182. http://dx.doi.org/10.1109/proc.1981.11950

[11] Pozar, D. (1995) The Analysis and Design of Microstrip Antennas and Arrays. IEEE Press, Piscataway. http://dx.doi.org/10.1109/9780470545270

[12] Zurcher, J.F. and Gardiol, F.E. (1995) Broadband Patch Antennas. Artech House, Norwood.

[13] Rusu, M.V. and Baican, R. (2010) Fractal Antenna Applications. In: Minin, I., Ed., Microwave and Millimeter Wave Technologies from Photonic Bandgap Devices to Antenna and Applications, Chap. 16, InTech, Rijeka, 351-382. http://dx.doi.org/10.5772/212

[14] Rusu, M.V., Hirvonen, M., Rahimi, H., Enoksson, P., Rusu, C., Pesonen, N., Vermesan, O. and Rustad, H. (2008) Minkowski Fractal Microstrip Antenna for RFID Tags. Proceedings of EuMW 2008 Symposium, Amsterdam, 27-31 October 2008, 666-669. 
[15] Rahimi, H., Rusu, M., Enoksson, P., Sandström, D. and Rusu, C. (2007) Small Patch Antenna Based on Fractal Design for Wireless Sensors. 18th Workshop on Micromachining, Micromechanics, and Microsystems, Guimaraes, 16-18 September 2007.

[16] Sabban, A. (2015) Low Visibility Antennas for Communication Systems. Taylor \& Francis Group, Boca Raton.

[17] Sabban, A. and Gupta, K.C. (1991) Characterization of Radiation Loss from Microstrip Discontinuities Using a Multiport Network Modeling Approach. IEEE Transactions on Microwave Theory and Techniques, 39, 705-712. http://dx.doi.org/10.1109/22.76436

[18] Sabban, A. (1981) A New Wideband Stacked Microstrip Antenna. IEEE Antenna and Propagation Symposium, Houston, June 1983.

[19] Sabban, A. (2011) Microstrip Antenna Arrays. In: Nasimuddin, N., Ed., Microstrip Antennas, InTech, Rijeka, $361-384$. http://dx.doi.org/10.5772/14394

[20] Sabban, A. (2013) New Wideband Printed Antennas for Medical Applications. IEEE Transactions on Antennas and Propagation, 61, 84-91. http://dx.doi.org/10.1109/TAP.2012.2214993

[21] Sabban, A. (2009) Wideband Printed Antennas for Medical Applications. APMC Conference, Singapore, 7-10 December 2009, 393-396. http://dx.doi.org/10.1109/apmc.2009.5384521

[22] Sabban, A. (2012) Wideband Tunable Printed Antennas for Medical Applications. IEEE Antenna and Propagation Society International Symposium, Chicago, 8-14 July 2012, 1-2. http://dx.doi.org/10.1109/aps.2012.6349023 